\title{
Texture Evolution and corrosion behaviour of Sn-Cr electrodeposited coatings.
}

Sahibzada Roohan Lala ${ }^{1}$, Kompella Jyotheender ${ }^{2}$, Abhay Gupta ${ }^{3}$, Sweety Arora ${ }^{4}$, Punith Kumar MK ${ }^{4}$ and Chandan Srivastava ${ }^{5}$

${ }^{1}$ IISc Banglore, Banglore, India, ${ }^{2}$ IISc-Bangalore, Bengaluru, Karnataka, India, ${ }^{3}$ IISc Bangalore, Karnataka, India, ${ }^{4}$ IISc, United States, ${ }^{5}$ IISc Bangalore, Bengaluru, Karnataka, India

Tin coatings are widely used over mild steel for anodic protection [1] and as interconnects in electronic circuits [2]. Failure of the electronic components generally occurs at the interconnects due to whisker formation and corrosion. This work focusses on the electrodeposition and microstructure-property correlations in $\mathrm{Sn}-\mathrm{Cr}$ coatings with minor $\mathrm{Cr}$ additions. As $\mathrm{Sn}$ and $\mathrm{Cr}$ form an immiscible system under equilibrium conditions [3], $\mathrm{Cr}$ is expected to segregate at the grain boundaries of $\mathrm{Sn}$ (in $\mathrm{Sn}-\mathrm{Cr}$ coatings) and prevent its dissolution from the high energy grain boundary regions when exposed to the corrosive environments.

$\mathrm{Sn}-\mathrm{Cr}$ coatings were electrodeposited over the mild steel substrate using direct current power supply. $\mathrm{SnSO}_{4}$ and $\mathrm{CrCl}_{3}$ salts were used as metallic precursors. Sodium gluconate was used as a complexing agent and $\mathrm{NH}_{4} \mathrm{Cl}$ acted as a buffer. The deposition was done at $\mathrm{pH}$ of 5, temperature was kept at $45^{\circ} \mathrm{C}$ and time of deposition was 40 minutes. Coatings with three different chromium compositions were prepared: $\mathrm{Sn}-1.3 \mathrm{wt} \% \mathrm{Cr}, \mathrm{Sn}-$ $3.3 \mathrm{wt} \% \mathrm{Cr}$ and $\mathrm{Sn}-5.4 \mathrm{wt} \% \mathrm{Cr}$. The as-prepared electrodeposited coatings were electrochemically characterised for corrosion properties using Tafel extrapolation and electrochemical impedance spectroscopy techniques. $\mathrm{Sn}-\mathrm{Cr}$ alloys having $1.3 \mathrm{wt} \% \mathrm{Cr}$ exhibited the best corrosion resistance in terms of lowest corrosion current density $\left(i_{\text {corr }}\right)$, highest polarisation resistance $\left(\mathrm{R}_{\mathrm{p}}\right)$ and lowest double layer capacitance $\left(\mathrm{Q}_{\mathrm{dl}}\right)$. Higher additions of $\mathrm{Cr}$ resulted in deterioration of the corrosion properties. The $\mathrm{i}_{\text {corr }}$ values obtained were $2.05 \mu \mathrm{A} / \mathrm{cm}^{2}, 1.19$ $\mu \mathrm{A} / \mathrm{cm}^{2}, 2.16 \mu \mathrm{A} / \mathrm{cm}^{2}, 1.65 \mu \mathrm{A} / \mathrm{cm}^{2}$ for Sn, Sn-1.3 wt\% Cr, Sn-3.3wt\% Cr and Sn-5.4wt\% Cr, respectively.

To understand the corrosion behaviour, microstructural analysis of the coatings was conducted using the scanning transmission electron microscopy (STEM) and electron back scatter diffraction (EBSD) methods. STEM-high angle annular dark field (STEM-HAADF) image, $\mathrm{Cr}$ and $\mathrm{Sn}$ compositional maps for $\mathrm{Sn}-\mathrm{Cr}$ (1.3 wt $\%$ and $3.3 \mathrm{wt} \%$ ) coating provided in Fig. 1(a-b) reveal the following: (1) There is a segregation of $\mathrm{Cr}$ at the grain boundaries of $\mathrm{Sn}$. (2) there are two types of grains present in the matrix: $\mathrm{Sn}$ grains and $\mathrm{Sn}-\mathrm{Cr}$ grains. EBSD images also revealed different types of grains based on the lattice strain values. Inverse pole figure (IPF) maps of pristine Sn and Sn-Cr (1.3 wt\%) coatings along the coating growth direction [100] are shown in Fig. 2(b). In the IPF maps, diffraction planes of pristine $\mathrm{Sn}$ and $\mathrm{Sn}-\mathrm{Cr}(1.3 \mathrm{wt} \%)$ coatings which are prominent from texture coefficient data (Fig. 2(f)) (from the analysis of the x-ray diffraction pattern) are highlighted. Intensity distribution in IPF map of pristine $\mathrm{Sn}$ and $\mathrm{Sn}-\mathrm{Cr}(1.3 \mathrm{wt} \%)$ coating signifies presence of dominant $\{110\}$ texture (which corresponds to (220) planes in Fig. 2(f)). Texture coefficient data and IPF indicates that the pristine Sn coating has high fraction of (240) planes followed by $\{110\}$ and $\mathrm{Cr}$ addition has enhanced texture with (011) plane orientation. Grain orientation spread (GOS) and grain reference orientation deviation (GROD) maps of coatings are shown in Fig. 2(c-d). The average orientation deviation within the grains of Sn-Cr (1.3 wt\%) coating show three different conditions specified in grains marked G1, G2 and G3. These suggest different strains present in different grains which is due to the differences in the amount of $\mathrm{Cr}$ present in each grain. Presence of $\mathrm{Cr}$ within the grains enhanced the strain within the grains. Upon exposure to the corrosive media ( $3 \mathrm{wt} \% \mathrm{NaCl}$ ), the "optimum" $\mathrm{Cr}$ (in case of $1.3 \mathrm{wt} \% \mathrm{Cr}$ ) segregates at the grain boundaries to form protective chromium oxides which enhances the corrosion resistance of the coating. Higher Cr contents (in case of $3.3 \mathrm{wt} \%$ and $5.5 \mathrm{wt} \% \mathrm{Cr}$ coatings) leads to the accumulation of higher strains within the coating grains which deteriorates the corrosion resistance properties of the coatings as the strained regions become anodic with respect to non-strained regions. 


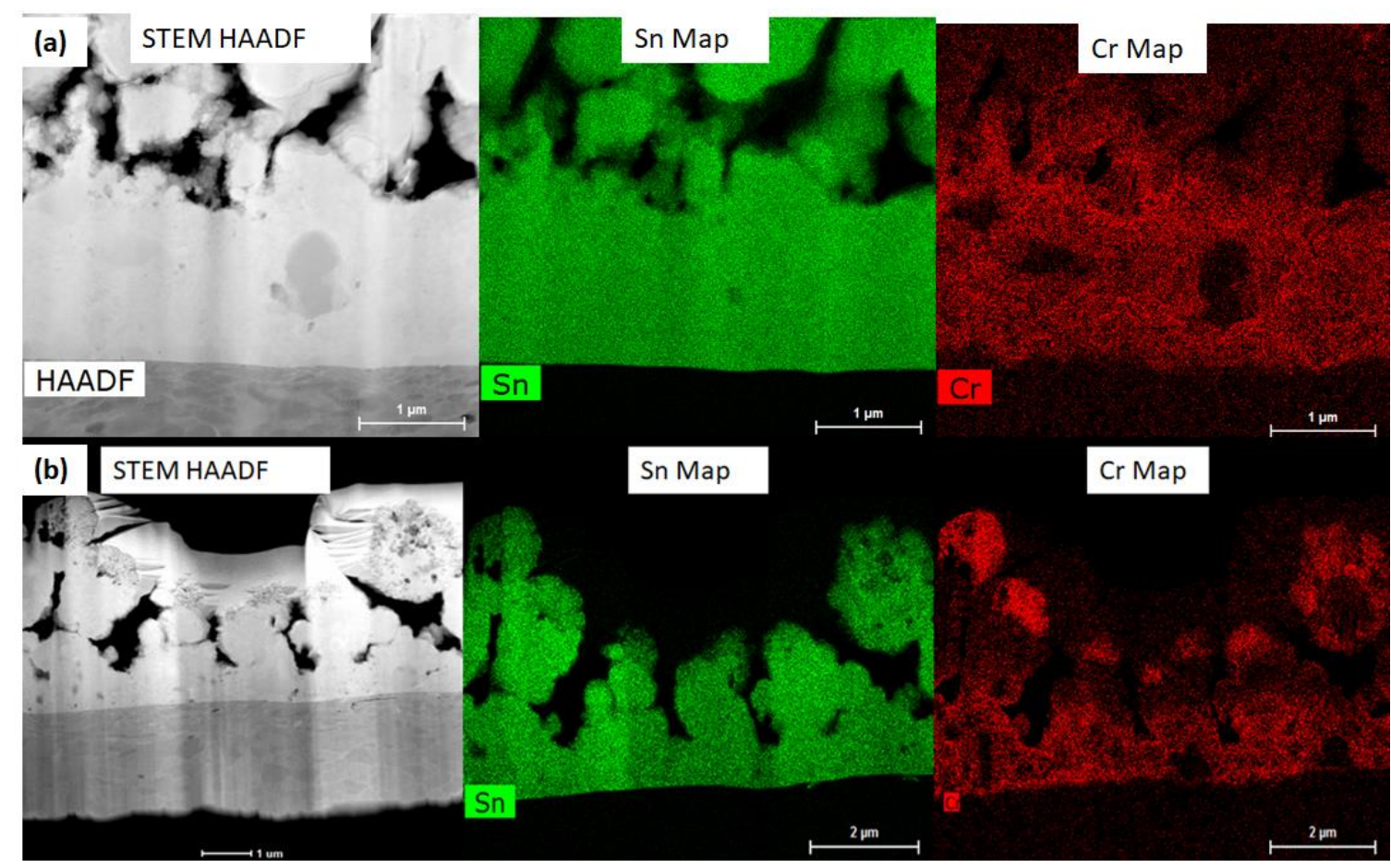

Figure 1. Figure. 1. STEM-HAADF field image, (a) $\mathrm{Cr}$ and $\mathrm{Sn}$ map for $\mathrm{Sn}-\mathrm{Cr}$ (1.3 wt\%) coating (b) Cr and $\mathrm{Sn}$ map for $\mathrm{Sn}-\mathrm{Cr}(3.3 \mathrm{wt} \%)$ coating
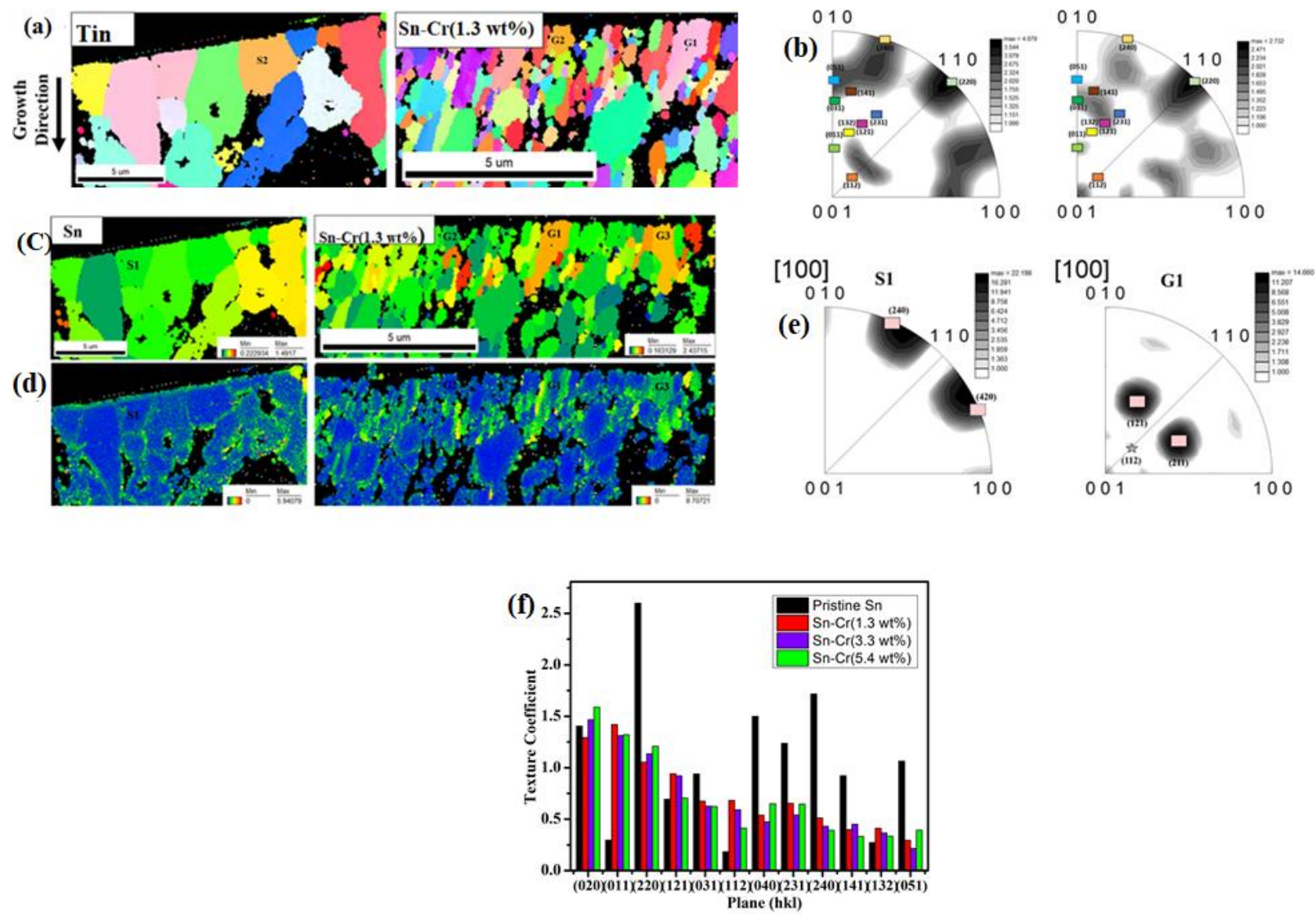
Figure 2. Figure.2 (a) Orientation distribution maps of pristine $\mathrm{Sn}$ and $\mathrm{Sn}-\mathrm{Cr}$ (1.3 wt\%) coating crosssection. (b) IPF maps for Pristine Sn and Sn-Cr (1.3 wt\%) coatings. (c) Grain orientation spread (GOS) (d) grain reference orientation deviation (GROD) cross-section (e) IPF maps of pristine Sn and Sn-Cr (1.3 wt\%) coatings (f) Texture coefficient obtained for the diffracting planes of Sn phase calculated from XRD peak intensities.

\section{References}

[1] O.L. Riggs and C.E. Locke, "Anodic Protection: Theory and Practice in the Prevention of Corrosion" Plenum Press, New York, (1981).

[2] Z.L. Ma , S.A. Belyakov , K. Sweatman , T. Nishimura , C.M. Gourlay , Nat. Commun. 8 (2017) 1916.

[3] M. Venkatraman, J.P. Neumann The Cr-Sn (Chromium-Tin) system J. Phase Equilibria., 9 (1988), pp. 159-162 